\title{
The Structural Basis for Isoform Selective Nitric Oxide Synthase Inhibition by Thiophene-2-Carboximidamides
}

\author{
Huiying Li ${ }^{1}$, Ryan J. Evenson ${ }^{2}$, Georges Chreifi ${ }^{1,3}$, Richard B. Silverman ${ }^{2,{ }^{*}}$, and Thomas L. \\ Poulos $^{1, *}$ \\ ${ }^{1}$ Departments of Molecular Biology and Biochemistry, Pharmaceutical Sciences, and Chemistry, \\ University of California, Irvine, California 92697-3900, United States \\ ${ }^{2}$ Department of Chemistry, Department of Molecular Biosciences, Chemistry of Life Processes \\ Institute, Center for Molecular Innovation and Drug Discovery, Northwestern University, 2145 \\ Sheridan Road, Evanston, Illinois 60208-3113, United States \\ ${ }^{3}$ Current address: Division of Biology and Biological Engineering, California Institute of \\ Technology, Pasadena, CA 91125, United States
}

\begin{abstract}
The over production of nitric oxide in the brain by neuronal nitric oxide synthase (nNOS) is associated with a number of neurodegenerative diseases. Although inhibiting nNOS is an important therapeutic goal, it is important not to inhibit endothelial NOS (eNOS) owing to the critical role played by eNOS in maintaining vascular tone. While it has been possible to develop nNOS selective aminopyridine inhibitors, many of the most potent and selective inhibitors exhibit poor bioavailability properties. Our group and others have turned to more biocompatible thiophene-2-carboximidamides (T2C) inhibitors as potential nNOS selective inhibitors. We have used crystallography and computational methods to better understand how and why 2 commercially developed T2C inhibitors exhibit selectivity for human nNOS over human eNOS. As with many of the aminopyridine inhibitors, a critical active site Asp residue in nNOS vs Asn in eNOS is largely responsible for controlling selectivity. We also present thermodynamic integration results to better understand the change in $\mathrm{pKa}$ and thus charge of inhibitors once bound to the active site. In addition, relative free energy calculations underscore the importance of enhanced electrostatic stabilization of inhibitors bound to the nNOS active site compared to eNOS.
\end{abstract}

\section{Graphical Abstract}

\footnotetext{
"Corresponding authors: Phone:+1 949824 7020, poulos@uci.edu (T.L.P); Phone:+1 847491 5653; r-silverman@ northwestern.edu. \$Coordinates and structure factors have been deposited in the Protein Data Base under accession numbers 6CIC, 6CID, 6CIE, and 6CIF.
} 


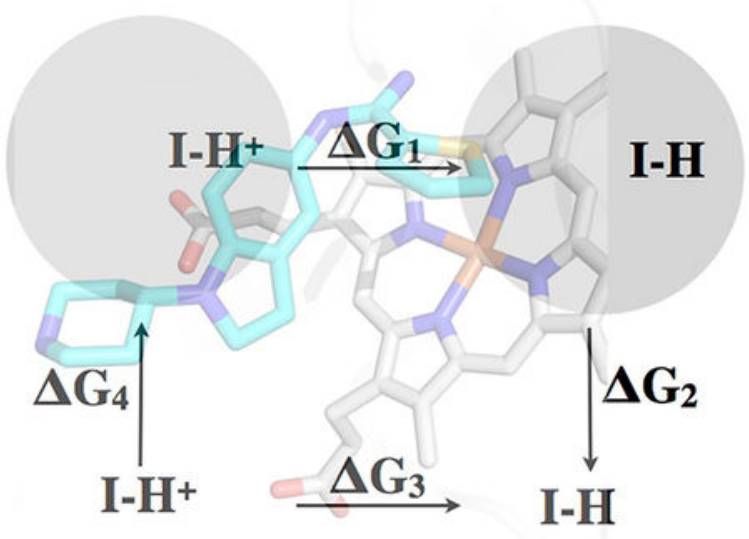

\section{Introduction}

Humans and other mammals have three nitric oxide synthase (NOS) isoforms that convert Larginine to L-citrulline and the potent signaling molecule, NO. ${ }^{1}$ Neuronal NOS (nNOS) participates in neural transmission, endothelial NOS (eNOS) regulates blood pressure, and NO generated by inducible NOS (iNOS) is part of macrophage host immune defense system. Given the potency of NO and its ability to cause oxidative damage, the overproduction of $\mathrm{NO}$ is associated with various pathological conditions, especially neurodegenerative diseases, ${ }^{2}$ so nNOS is an important therapeutic target. However, a major problem in NOS inhibitor design is selectivity. It is especially important not to block eNOS, owing to its central role in maintaining vascular tone. This is a challenging problem given that the active site of all three human isoforms is so similar. Nevertheless, it has been possible to develop aminopyridine inhibitors that are $\sim 4,000$-fold more selective for nNOS over eNOS. ${ }^{3}$ Some of these aminopyridine inhibitors exhibit remarkable neuroprotective effects in a cerebral palsy rabbit model. ${ }^{4}$ In these studies nNOS-selective inhibitors were found to protect rabbit fetuses from experimentally induced ischemic brain damage, which in saline control animal resulted in death or severe cerebral palsy symptoms. ${ }^{4}$ Despite the excellent selectivity of these aminopyridine inhibitors, the number of high $\mathrm{pKa}$ ionizable groups and the large number of rotatable bonds are not optimal for blood-brain barrier penetration and thus limit the potential usefulness of these compounds as neurodegenerative drugs. ${ }^{5}$

Early on in NOS drug development, thiophene-2-carboximidamide (T2C) inhibitors showed better biological properties ${ }^{6}$ and also were found to exhibit in vivo efficacy. ${ }^{7,8}$ Unfortunately, early generation $\mathrm{T} 2 \mathrm{C}$ inhibitors displayed poor isoform selectivity, $\sim 100$-fold for nNOS over eNOS. ${ }^{6}$ Further development of T2C inhibitors by NeurAxon has resulted in inhibitors that are up to 300-400 fold more selective for nNOS over eNOS. ${ }^{7,8}$ Moreover, some of these T2C inhibitors show promise in the treatment of migraine headaches ${ }^{8}$ and neuropathic pain. ${ }^{7}$ Another potential target for $\mathrm{T} 2 \mathrm{C}$ inhibitors is melanoma. $\mathrm{nNOS}$ is upregulated in various melanoma cell lines ${ }^{9,10}$, and NO increases cell invasiveness while nNOS inhibitors block melanoma cell growth (e.g., 1, Fig. 1). ${ }^{9,10}$. These studies illustrate that there must be a balance between isoform selectivity (up to 4,000-fold with some aminopyridines, e.g., $\mathbf{4}$, 
Fig. 1) and better drug-like properties of the T2C inhibitors, although the best selectivity so far is in the range of 500-fold. In this report we have analyzed two of the best NeurAxon inhibitors ( $\mathbf{2}$ and $\mathbf{3}$, Fig. 1) that show promising in vivo properties and compare these with our previous work on $\mathrm{T} 2 \mathrm{C}$ inhibitors. These analyses, including crystal structures and computational approaches, also shed light on general principles of NOS inhibition and isoform selectivity.

\section{Methods}

\section{Computational Approaches}

Amber 9 or 14 was used for MM_PBSA and thermodynamic integration (TI) calculations. Inhibitor parameters were assigned using the GAFF force field ${ }^{12}$ and AM1-BCC charge scheme, ${ }^{13,14}$ as implemented in the Antechamber module in Amber. Heme parameters were taken from Shahrokh et al. ${ }^{15}$ No specific bond parameters were used for the tetrahedral $\mathrm{Zn}^{2+}$ site located at the dimer interface and coordinated by pairs of symmetry related Cys residues. Instead, the 4 Cys ligands were modeled as Amber CYM residues that have an unprotonated side chain sulfur. The $\mathrm{Zn}^{2+}$ remained quite stable with excellent tetrahedral geometry during the simulations. Structures were energy minimized in 3 steps: 1) five hundred cycles of steepest decent followed by 500 cycles of conjugate gradient with only solvent molecules and $\mathrm{H}$ atoms allowed to move; 2) the same protocol with all atoms except the inhibitor and heme allowed to move; 3) 1000 cycles of steepest decent followed by 4000 cycles of conjugate gradient with all atoms allowed to move. For molecular dynamics simulations production runs were carried out using a time step of $2 \mathrm{fs}$ and coordinates saved every $20 \mathrm{ps}$ and Langevin dynamics using a collision frequency of $1 \mathrm{ps}^{-1}$. Periodic boundary conditions were used with a Particle Mesh Ewald implementation of the Ewald sum for the description of long-range electrostatic interactions. ${ }^{16}$ In all simulations crystallographically identified ordered water molecules were included.

The relative free energy of binding of various NOS inhibitors was estimated with MM_PBSA ${ }^{17}$ as implemented in Amber 9 and 14 using procedures developed in our earlier studies with NOS inhibitors. ${ }^{18}$ In this method the total free energy of the NOS-inhibitor complex is taken as the sum of the following energy terms,

$$
\mathrm{G}=\mathrm{E}_{\mathrm{MM}}+\mathrm{G}_{\text {solv }}+\mathrm{G}_{\mathrm{np}}-\mathrm{TS}_{\text {solute }}
$$

where $\mathrm{E}_{\mathrm{MM}}=$ the total molecular mechanics energy computed with the Sander module in Amber, $G_{\text {solv }}$ is the solvation free energy estimated from the Poisson-Boltzman equation, $\mathrm{G}_{\mathrm{np}}=$ the nonpolar solvation energy estimated from the solvent accessible surface area, and $\mathrm{TS}_{\text {solute }}=$ the solute entropy. $\mathrm{G}$ was computed for the NOS-inhibitor complex $\left(\mathrm{G}_{\text {complex }}\right)$, NOS alone with the inhibitor removed $\left(\mathrm{G}_{\text {receptor }}\right)$, and the inhibitor alone $\left(\mathrm{G}_{\text {inhibitor }}\right)$. The overall free energy of binding was computed from the following equation:

$$
\Delta \mathrm{G}_{\text {bind }}=\left(\mathrm{G}_{\text {complex }}-\mathrm{G}_{\text {receptor }}-\mathrm{G}_{\text {inhibitor }}\right)
$$


As others have done ${ }^{19}$ the change in solute entropy was ignored. Given that we are comparing exactly the same inhibitor bound to different active sites, ignoring solute entropy introduces little error, although only relative and not absolute free energies can be compared. Similar to what others have found, ${ }^{20}$ using a single energy minimized structure rather than molecular dynamics averages gives better agreement with experimental data. ${ }^{11,18}$ This is especially true for inhibitors where the electron density is well defined.

The change in $\mathrm{p} K \mathrm{a}$ of the inhibitors bound to the enzyme was estimated using thermodynamic integration (TI) procedures developed by Simonson et al. ${ }^{21}$ In this method the charge of the inhibitor in the protonated state is changed in incremental steps from $\lambda=0$ to $\lambda=1$ to the charge in the unprotonated state. Integration of the potential energy as a function of $\lambda$ gives the $\Delta \mathrm{G}$ in moving from one state to the other. The potential energy, $U$, was assumed to vary linearly with $\lambda$

$$
\mathrm{U}(\lambda)=(1-\lambda) \mathrm{U}_{\mathrm{A}}+\lambda \mathrm{U}_{\mathrm{B}}
$$

where $\mathrm{U}_{\mathrm{A}}$ is starting protonated state and $\mathrm{U}_{\mathrm{B}}$ unprotonated. Part of the program output is

$$
\partial \mathrm{U} / \partial \lambda=\mathrm{U}_{\mathrm{B}}-\mathrm{U}_{\mathrm{A}}=\Delta \mathrm{U}
$$

The overall $\Delta \mathrm{G}$ was computed in most cases using $5 \lambda$ steps together with the associated weights provided in the Amber manual.

$$
\begin{aligned}
& \Delta \mathrm{G}=0.11846\left(\Delta \mathrm{U}_{\lambda=. .04691}\right)+0.23931\left(\Delta \mathrm{U}_{\lambda=0.23076}\right)+0.28444\left(\Delta \mathrm{U}_{\lambda=0.5}\right)+0.23931( \\
& \left.\Delta \mathrm{U}_{\lambda=0.95308}\right)+0.11846\left(\Delta \mathrm{U}_{\lambda=0.76923}\right)
\end{aligned}
$$

To help speed the calculations by taking larger time steps, hydrogen mass repartitioning using parmed.py ${ }^{22}$ was used to modify the Amber topology file. Parmed.py also was used to change the charges on inhibitor atoms as needed and set the Lennard Jones terms to 0 for the titrating $\mathrm{H}$ atom. The NOS dimer with crystallographic waters with no additional solvent was first energy minimized followed by 1 ns simulation with no periodic boundary. Heavy atoms were restrained with $5 \mathrm{kcal} / \mathrm{mol}$ weight. We also carried out periodic boundary simulations with counterions to maintain neutrality. There was no significant difference in the results very likely because both periodic and nonperodic simulations had the same crystallographically identified active site solvent structure. Therefore, the results reported here are for simulations with no additional solvent or periodic boundary which substantially decreases computational time. However, for the inhibitors alone a fully solvated periodic boundary $2 \mathrm{~ns}$ simulation were carried out. The $\mathrm{p} K \mathrm{a}$ when bound to the protein was obtained by the following equation:

$$
\mathrm{p} K \mathrm{a}_{\text {protein }}=\mathrm{p} K \mathrm{a}_{\text {model }}+(1 / 2.303 \mathrm{RT}) * \Delta \Delta \mathrm{G}
$$


The $\mathrm{p} K \mathrm{a}$ of the inhibitor free in solution was estimated using ChemAxon software (http:// www.chemaxon.com)

\section{Inhibitor Complex Crystal Preparation.}

The sitting drop vapor diffusion methods were used to grow crystals at $4^{\circ} \mathrm{C}$ for the heme domains of human nNOS R354A/G357D mutant $(10 \mathrm{mg} / \mathrm{mL})$ and human eNOS $(7 \mathrm{mg} / \mathrm{mL})$. The mutations used for nNOS are located on the surface far from the active site, either to provent additional trypsin cleavage (R354A) or to improve crystal quality (G357D). ${ }^{23}$ The crystal growth conditions are as described previously ${ }^{24}$ except that the $\mathrm{pH}$ for human eNOS was mistakenly reported as 6.5 rather than 7.5 as in the original report. ${ }^{23}$ Fresh crystals were first passed stepwise through cryoprotectant solutions and then soaked with $10 \mathrm{mM}$ inhibitor for 3-4 $\mathrm{h}$ at $4^{\circ} \mathrm{C}$ before being flash cooled with liquid nitrogen and stored until data collection. The high concentration of magnesium acetate in the human eNOS growth conditions may also introduce an acetate ion near the active site, as was previously observed in some of the bovine eNOS structures. The presence of this acetate ion can influence the binding mode of inhibitors. To avoid having this acetate ion in the structure, the magnesium acetate $(250 \mathrm{mM})$ in the cryoprotectant solution was replaced with $\mathrm{MgCl}_{2}(100 \mathrm{mM})$.

\section{X-ray Diffraction Data Collection, Data Processing, and Structural Refinement.}

Cryogenic (100 K) X-ray diffraction data were collected remotely at the Stanford Synchrotron Radiation Lightsource (SSRL) through the data collection control software Blu$\mathrm{Ice}^{25}$ and a crystal-mounting robot. When a CCD detector was used data were typically collected with $0.5^{\circ}$ per frame. If a Pilatus pixel array detector was used fine-sliced data were collected with a $0.2^{\circ}$ per frame. Raw CCD data frames were indexed, integrated, and scaled using iMOSFLM, ${ }^{26}$ but the pixel array data were processed with $\mathrm{XDS}^{27}$ and scaled with Aimless. ${ }^{28}$ The binding of inhibitors was detected by initial difference Fourier maps calculated with REFMAC. ${ }^{29}$ The inhibitor molecules were then modeled in $\operatorname{Coot}^{30}$ and refined using REFMAC or PHENIX. ${ }^{31}$ The crystal packing of the $\mathrm{MgCl}_{2}$ soaked heNOS crystals was changed slightly, resulting in a symmetry change from the orthorhombic $\mathrm{P} 2{ }_{1} 2_{1} 2_{1}$ reported previously ${ }^{23}$ to monoclinic $\mathrm{P} 2{ }_{1}$, with a $\beta$ angle only $0.6-0.7^{\circ}$ off compared to the original $90^{\circ}$. Therefore, a molecular replacement calculation with PHASER-MR ${ }^{32}$ was needed to solve the structure. In the $\mathrm{P} 22_{1}$ space group, there are two heNOS dimers in the asymmetric unit. Water molecules were added in PHENIX and checked by Coot. The TLS ${ }^{33}$ protocol was implemented in the refinements with each subunit as one TLS group. The Polder map facility in PHENIX was used to calculate the omit density map for the bound inhibitors. ${ }^{34}$ The refined structures were validated in Coot before deposition in the Protein Data Bank. Data collection and structure refinement statistics are summarize in Table S1 (supporting information).

Synthesis - Compounds $\mathbf{2}$ and $\mathbf{3}$ were synthesized according to published procedures. ${ }^{7,8}$ 


\section{Results and Discussion}

\section{Crystal Structures}

The crystal structures of nNOS complexed to $\mathbf{2}$ and $\mathbf{3}$ were solved to a resolution of $1.75 \AA$ while the structures of eNOS complexed to $\mathbf{2}$ and $\mathbf{3}$ were solved to a resolution of $1.95 \AA$ and $2.20 \AA$, respectively (Table S1). The electron density for both $\mathbf{2}$ and $\mathbf{3}$, with the exception of the tail end of $\mathbf{2}$, is very clear, enabling an unambiguous positioning of both inhibitors. As in our previous structures of $\mathrm{T} 2 \mathrm{C}$ inhibitors, the $\mathrm{T} 2 \mathrm{C}$ group is in position to form ionic interactions with the active site Glu (Fig. 2).

The central tetrahydroquinoline ring of $\mathbf{2}$ and the indoline ring of $\mathbf{3}$ occupy nearly identical positions in human nNOS. The tail end tertiary amine of $\mathbf{2}$ is $3.7 \AA$ from heme propionate A, while the $\mathrm{N}$ atom of the tail piperidine of $\mathbf{3}$ is $5.7 \AA$ from heme propionate A. Since neither of them form a good $\mathrm{H}$-bonding interaction, this difference appears not to be very significant, as the reported $I C_{50}$ values for both compounds with nNOS are very similar, $0.097 \mu \mathrm{M}$ for $\mathbf{2}^{7}$ and $0.11 \mu \mathrm{M}$ for $\mathbf{3}^{8}{ }^{8}$ Figure 3 shows the previously published structures of $\mathbf{1}$ bound to rat nNOS. 1 is a potent nNOS inhibitor $\left(K_{\mathrm{i}} \sim 0.005 \mu \mathrm{M}\right)$ with an e/n selectivity of $\sim$ $540 .{ }^{10}$ In 1 this central bridging amine is situated between both propionates at distances of $3.4 \AA$ and $3.8 \AA$ A (Figure 3B).

With 1, propionate D is able to move "up" toward the inhibitor for better interactions with the inhibitor central amine. This cannot happen with $\mathbf{2}$ and $\mathbf{3}$ since the central tetrahydroquinoline or indoline ring would cause steric clashes with propionate $\mathrm{D}$. These differences and the better interactions between the bridging amine could possibly account for why $\mathbf{1}$ is about 20 -fold better as an inhibitor than either $\mathbf{2}$ or $\mathbf{3}$.

\section{Estimating Inhibitor pKas Using Thermodynamic Integration}

Previous work from our labs has shown that many inhibitors bind more tightly to nNOS than eNOS owing primarily to a single amino acid difference: nNOS has Asp597 where eNOS has Asn368 at that location (Fig. 3). ${ }^{3,35}$ A majority of this effort centered on rat nNOS and bovine eNOS, and while we expect the human isoforms to behave similarly, there are far fewer data probing the Asp/Asn difference (Asp602 in human nNOS and Asn366 in human eNOS) in the human isoforms. We therefore probed the influence of this single amino acid difference using the MM_PBSA method that proved quite useful in our previous studies. ${ }^{18}$ However, given that NOS inhibitors have at least one and usually more titratable groups, it is important to know if there is a significant change in pKa once bound to the active site so that the correct charge can be assigned to the inhibitor for free energy calculations.

Thermodynamic integration methods, where the energy change in moving from the protonated state to the un-protonated state in solution vs. in the protein, most often is used to estimate the change in $\mathrm{p} K \mathrm{a}$ of amino acid side chains in proteins. ${ }^{21}$ In principle it should be possible to use the same computational methods to estimate the $\Delta \mathrm{p} K$ a by comparing the $\Delta \mathrm{G}$ (protonated to un-protonated) free in solution and bound to the protein. Both $\mathbf{2}$ and $\mathbf{3}$ have 3 titratable $\mathrm{N}$ atoms whose $\mathrm{p} K$ a could change once bound to the protein. The ring nitrogens of the tetrahydroquinoline of $\mathbf{2}$ and indoline of $\mathbf{3}$ have estimated $\mathrm{p} K$ a values of $\sim 1.9$ and 3.2, respectively. The tail end tertiary $\mathrm{N}$ atom of $\mathbf{2}$ and the piperidine $\mathrm{N}$ atom of $\mathbf{3}$ give estimated 
$\mathrm{p} K$ a values of 9.2 and 9.8, respectively. Therefore, neither of these groups is expected to change protonation state once bound to NOS. The only $\mathrm{p} K \mathrm{a}$ in question when bound to the NOS active site is the T2C group with an estimated $\mathrm{p} K \mathrm{a} \sim 6.98$ in both $\mathbf{2}$ and $\mathbf{3}$. Since the T2C group is buried in the active site near the conserved Glu, the $\mathrm{pKa}$ could increase substantially. The results of the thermodynamic integrations are shown in Table 1 and Tables S2 and S3. Two simulations were carried out. One for the nNOS-2 complex using a 3-step integration and the second for the eNOS-3 complex with a 5-step integration. The titrating $\mathrm{H}$ atom is the large $\mathrm{H}$ atom shown in Table 1 and Tables $\mathrm{S} 2$ and $\mathrm{S} 3$. In both cases there is a substantial increase in $\mathrm{pKa}$ when bound to NOS, indicating that T2C group is fully protonated when bound to the active site. The increase in $\mathrm{pKa}$ in nNOS is substantially more than in eNOS. Since this is probably due to the Asn vs Asp difference, we generated the Asn366Asp mutant in silico and reran the TI calculations for eNOS-3 complex. The $\mathrm{pKa}$ increases even further, which indicates that the Asp in nNOS vs. Asn in eNOS contributes to additional stability of the $\mathrm{T} 2 \mathrm{C}$ group buried in the active site. We also carried out a TI run for the nNOS D602N mutant. As expected, the pKa of $\mathbf{2}$ drops relative to wild type nNOS again illustrating the important role the Asp vs. Asn difference has on the pKa of the T2C group. Therefore, any functional group with a $\mathrm{p} K$ a near neutrality that is buried in the NOS active site and interacts with the conserved Glu will be fully protonated in both nNOS and eNOS.

As a basis for comparison, we carried out TI calculation on other $\mathrm{N}$ atoms. The tetrahydroquinoline $\mathrm{N}$ atom of $\mathbf{2}$ has an estimated $\mathrm{p} K \mathrm{a} \sim 2$, while the indoline ring $\mathrm{N}$ atom of 3 has an estimated $\mathrm{p} K \mathrm{a} \sim 3$. Both of these atoms are within $\sim 4.3 \AA$ of the heme propionate A (Figure 3), so there could potentially be an increase in $\mathrm{p} K$ a. However, TI calculations indicate that the tetrahydroquinoline $\mathrm{N}$ atom of $\mathbf{2}$ does experience a significant shift in $\mathrm{pKa}$ when bound to nNOS (Table S4). This part of the inhibitor extends out toward solvent and is near two Arg residues at a distance of $5.7 \AA$ and $6.4 \AA$. It thus appears that the proximity of the tail end of the inhibitors near both a heme propionate and Arg residues results in no net change in $\mathrm{pKa}$.

\section{Relative Binding Free Energy}

For the MM_PBSA calculations, we used only $\mathbf{3}$ since the tail end of $\mathbf{2}$ is not well ordered in eNOS, while with $\mathbf{3}$, the electron density is well ordered in both isoforms. When bound to the protein, $\mathbf{3}$ was modeled as carrying a net +2 charge since the calculations summarized in Table 1 show that the T2C group is fully protonated. However, free in solution the T2C group is about $50 \%$ protonated since the estimated $\mathrm{p} K \mathrm{a}$ is $\sim 6.98$. Therefore, free in solution 3 was modeled as carrying a net +1.5 charge. The partially protonated state was modeled by averaging the charges of the +1 and +2 models. Results from the MM_PBSA calculations are shown in Table 2.

In addition to $\Delta \mathrm{G}_{\text {calc }}$, also shown in Table 2 is the change in just the electrostatic component $\triangle \mathrm{ELEC}_{\mathrm{calc}}$. The normalized calculated values are quite close to the range of experimental values derived from $K_{\mathrm{i}}$ measurements, although $\triangle \mathrm{ELEC}_{\text {calc }}$ agrees best. This is probably due to the dominance of electrostatics as the key component in controlling isoform selectivity 
and shows that the Asp/Asn difference accounts for nearly all of the selectivity for nNOS over eNOS.

The distance between the Asp or Asn from the closest inhibitor $\mathrm{N}$ atom is too far, $\sim 7-9 \AA$ (Figure 3), for direct ionic or H-bonding interactions. Nevertheless, charge-charge interactions depend on the dielectric milieu, and in the confines of the active site, these interactions are expected to be substantially stronger than in solvent.

\section{Conclusions}

A comparison between NeurAxon inhibitors $\mathbf{2}$ and $\mathbf{3}$ with our inhibitor $\mathbf{1}$ illustrates the critical role that electrostatic and ionic interactions play in inhibitor potency. The better electrostatic interactions between $\mathbf{1}$ and the active site account for why $\mathbf{1}$ is a better inhibitor. These properties of good NOS inhibitors also present a challenge. The NOS active site is charged owing to the conserved buried Glu residue, the heme propionates, and several Arg residues lining the entrance to the active site. As might be expected, the best inhibitors have charged groups that strongly interact primarily with the conserved active site Glu and heme propionates. As we have shown, subtle electrostatic differences between eNOS and nNOS can be exploited for enhanced selectivity. The key here is Asp602 in nNOS vs. Asn366 in eNOS. Although the Asp/Asn does not directly contact any inhibitor atom, the long-range electrostatic effects in the confines of the active site apparently has a large effect. Another new insight from the present study is the change of $\mathrm{p} K$ a of the inhibitor when free or bound. An ideal inhibitor should be unprotonated when free in solution for bioavailability but once bound becomes protonated for optimal interactions with active site groups. Our current results coupled with previous studies make it clear that nNOS vs eNOS selectivity is greatest for those inhibitors with multiple charged groups that exploit the Asp/Asn difference. It thus appears that in the design of nNOS selective inhibitors a balance must be achieved between selectivity and bioavailability.

\section{Supplementary Material}

Refer to Web version on PubMed Central for supplementary material.

\section{Acknowledgements}

We wish to thank the Stanford Synchrotron Radiation Lab and the Advanced Light Source beamline staff for their support during remote X-ray diffraction data collection. We also acknowledge the San Diego Supercomputer Center.

This work was supported by NIH grants GM57353 (TLP) and GM049725 (RBS)

\section{References}

(1). Stuehr DJ; Griffith OW (1992) Mammalian nitric oxide synthases. Adv. Enzymol. Relat. Areas Mol. Biol 65, 287-346. [PubMed: 1373932]

(2). Calabrese V; Mancuso C; Calvani M; Rizzarelli E; Butterfield DA; Stella AM (2007) Nitric oxide in the central nervous system: neuroprotection versus neurotoxicity. Nat. Rev. Neurosci 8, 766775. [PubMed: 17882254] 
(3). Silverman RB (2009) Design of selective neuronal nitric oxide synthase inhibitors for the prevention and treatment of neurodegenerative diseases. Acc. Chem. Res 42, 439-451. [PubMed: 19154146]

(4). Ji H; Tan S; Igarashi J; Li H; Derrick M; Martasek P; Roman LJ; Vasquez-Vivar J; Poulos TL; Silverman RB (2009) Selective neuronal nitric oxide synthase inhibitors and the prevention of cerebral palsy. Ann. Neurol 65, 209-217. [PubMed: 19235180]

(5). Mukherjee P; Cinelli MA; Kang S; Silverman RB (2014) Development of nitric oxide synthase inhibitors for neurodegeneration and neuropathic pain. Chem. Soc. Rev 43, 6814-6838. [PubMed: 24549364]

(6). Reif DW; McCarthy DJ; Cregan E; Macdonald JE (2000) Discovery and development of neuronal nitric oxide synthase inhibitors. Free Radic. Biol. Med 28, 1470-1477. [PubMed: 10927171]

(7). Ramnauth J; Renton P; Dove P; Annedi SC; Speed J; Silverman S; Mladenova G; Maddaford SP; Zinghini S; Rakhit S; Andrews J; Lee DK; Zhang D; Porreca F (2012) 1,2,3,4tetrahydroquinoline-based selective human neuronal nitric oxide synthase (nNOS) inhibitors: lead optimization studies resulting in the identification of $\mathrm{N}$-(1-(2-(methylamino)ethyl)-1,2,3,4tetrahydroquinolin-6-yl)thiophene-2-carboximi damide as a preclinical development candidate. J. Med. Chem 55, 2882-2893. [PubMed: 22335555]

(8). Annedi SC; Maddaford SP; Ramnauth J; Renton P; Rybak T; Silverman S; Rakhit S; Mladenova G; Dove P; Andrews JS; Zhang D; Porreca F (2012) Discovery of a potent, orally bioavailable and highly selective human neuronal nitric oxide synthase (nNOS) inhibitor, N-(1-(piperidin-4yl)indolin-5-yl)thiophene-2-carboximidamide as a pre-clinical development candidate for the treatment of migraine. Eur. J. Med. Chem 55, 94-107. [PubMed: 22840695]

(9). Yang Z; Misner B; Ji H; Poulos TL; Silverman RB; Meyskens FL; Yang S (2013) Targeting nitric oxide signaling with nNOS inhibitors as a novel strategy for the therapy and prevention of human melanoma. Antioxid. Redox Signal 19, 433-447. [PubMed: 23199242]

(10). Huang H; Li H; Yang S; Chreifi G; Martasek P; Roman LJ; Meyskens FL; Poulos TL; Silverman RB (2014) Potent and selective double-headed thiophene-2-carboximidamide inhibitors of neuronal nitric oxide synthase for the treatment of melanoma. J. Med. Chem 57, 686-700. [PubMed: 24447275]

(11). Delker SL; Ji H; Li H; Jamal J; Fang J; Xue F; Silverman RB; Poulos TL (2010) Unexpected binding modes of nitric oxide synthase inhibitors effective in the prevention of a cerebral palsy phenotype in an animal model. J. Am. Chem. Soc 132, 5437-5442. [PubMed: 20337441]

(12). Wang J; Wolf RM; Caldwell JW; Kollman PA; Case D (2004) Development and testing of a general Amber force fiedl. J. Amer. Chem. Soc 25, 1157-1174.

(13). Jakalian A; Bush BL; Jack DB; Bayly CI (2000) Fast, efficient generation of high-quality atom charges. AM1-BCC model: I. Method. J. Comp. Chem 21, 132-146.

(14). Jakalian A; Jack DB; Bayly CI (2002) Fast, efficient generation of high-quality atom charges. AM1-BCC model: II. Parameterization and validation. J. Comp. Chem 23, 1623-1641. [PubMed: 12395429]

(15). Shahrokh K; Orendt A; Yost GS; Cheatham TE, 3rd (2012) Quantum mechanically derived AMBER-compatible heme parameters for various states of the cytochrome P450 catalytic cycle. J. Comput. Chem 33, 119-133. [PubMed: 21997754]

(16). Darden T; Perera L; Li L; Pedersen L (1999) New tricks for modelers from the crystallography toolkit: the particle mesh Ewald algorithm and its use in nucleic acid simulations. Structure 7, R55-60. [PubMed: 10368306]

(17). Massova I; Kollman PA (1999) Computational alanine scanning to probe protein-protein interactions: A novel approach to evaluate binding free energies. J. Amer. Chem. Soc 8133-8143.

(18). Igarashi J; Li H; Jamal J; Ji H; Fang J; Lawton GR; Silverman RB; Poulos TL (2009) Crystal structures of constitutive nitric oxide synthases in complex with de novo designed inhibitors. J. Med. Chem 52, 2060-2066. [PubMed: 19296678]

(19). Brown SP; Muchmore SW (2006) High-througput calculation of protein-ligand binding affinities: Modification and adaption of the MM-PBSA protocol to enterprise grdi computing. J. Chem. Inf. Model 46, 999-1005. [PubMed: 16711718] 
(20). Kuhn B; Gerber P; Schulz-Gasch T; Stahl M (2005) Validation and use of the MM-PBSA approach for drug discovery. J. Med. Chem 48, 4040-4048. [PubMed: 15943477]

(21). Simonson T; Carlsson J; Case DA (2004) Proton binding to proteins: pK(a) calculations with explicit and implicit solvent models. J. Am. Chem. Soc 126, 4167-4180. [PubMed: 15053606]

(22). Hopkins CW; Le Grand S; Walker RC; Roitberg AE (2015) Long-Time-Step Molecular Dynamics through Hydrogen Mass Repartitioning. J. Chem. Theory Comput 11, 1864-1874. [PubMed: 26574392]

(23). Li H; Jamal J; Plaza C; Pineda SH; Chreifi G; Jing Q; Cinelli MA; Silverman RB; Poulos TL (2014) Structures of human constitutive nitric oxide synthases. Acta Crystallogr. D Biol. Crystallogr D70, 2667-2674.

(24). Cinelli MA; Li H; Chreifi G; Poulos TL; Silverman RB (2017) Nitrile in the Hole: Discovery of a Small Auxiliary Pocket in Neuronal Nitric Oxide Synthase Leading to the Development of Potent and Selective 2-Aminoquinoline Inhibitors. J. Med. Chem 60, 3958-3978. [PubMed: 28422508]

(25). McPhillips TM; McPhillips SE; Chiu HJ; Cohen AE; Deacon AM; Ellis PJ; Garman E; Gonzalez A; Sauter NK; Phizackerley RP; Soltis SM; Kuhn P (2002) Blu-Ice and the Distributed Control System: software for data acquisition and instrument control at macromolecular crystallography beamlines. J. Synchrotron Radiat 9, 401-406. [PubMed: 12409628]

(26). Battye TGG; Kontogiannis L; Johnson O; Powell HR; Leslie AGW (2011) iMOSFLM: a new graphical interface for diffraction-image processing with MOSFLM. Acta Crystallogr. D Biol. Crystallogr D67, 271-281.

(27). Kabsch W (2010) XDS. Acta Crystallogr. D Biol. Crystallogr 66, 125-132. [PubMed: 20124692]

(28). Evans PR (2006) Scaling and assessment of data quality. Acta Crystallogr. D Biol. Crystallogr D62, 72-82.

(29). Murshudov GN; Vagin AA; Dodson EJ (1997) Refinement of Macromolecular Structures by the Maximum-Likelihood Method. Acta Crystallogr. D Biol. Crystallogr D53, 240-255.

(30). Emsley P; Cowtan K (2004) Coot: model-building tools for molecular graphics. Acta Crystallogr. D Biol. Crystallogr D60, 2126-2132.

(31). Adams PD; Afonine PV; Bunkoczi G; Chen VB; Davis IW; Echols N; Headd JJ; Hung L-W; Kapral GJ; Grosse-Kunstleve RW; McCoy AJ; Moriarty NW; Oeffner R; Read RJ; Richardson DC; Richardson JS; Terwilliger TC; Zwart PH (2010) PHENIX: a comprehensive Python-based system for macromolecular structure solution. Acta Crystallogr. D Biol. Crystallogr D66, 213221.

(32). McCoy AJ; Grosse-Kunstleve RW; Adams PD; Winn MD; Storoni LC; Read RJ (2007) Phaser crystallographic software. J. Appl. Crystallog 40, 658-674.

(33). Winn MD; Isupov MN; Murshudov GN (2001) Use of TLS parameters to model anisotropic displacements in macromolecular refinement. Acta Crystallogr. D Biol. Crystallogr D57, 122133.

(34). Liebschner D; Afonine PV; Moriarty NW; Poon BK; Sobolev OV; Terwilliger TC; Adams PD (2017) Polder maps: improving OMIT maps by excluding bulk solvent. Acta Crystallogr. D Biol. Crystallogr D73, 148-157.

(35). Poulos TL; Li H (2013) Structural basis for isoform-selective inhibition in nitric oxide synthase. Acc. Chem. Res 46, 390-398. [PubMed: 23030042] 
<smiles>N=C(Nc1ccc(CCNCc2cccc(NC(=[NH2+])c3cccs3)c2)cc1)c1cccs1</smiles><smiles>CC[NH+](C)CCN1CCCc2cc(NC(=[NH2+])c3cccs3)ccc21</smiles>

$\mathrm{K}_{\mathrm{i}} \mathrm{nNOS}=0.005 \mu \mathrm{M}$

$\mathrm{K}_{\mathrm{i}}$ eNOS $=2.7 \mu \mathrm{M}$

$\mathrm{e} / \mathrm{n}=\mathbf{5 4 0}$

$\mathrm{IC}_{50}$ nNOS $=0.097 \mu \mathrm{M}$

$\mathrm{IC}_{50}$ eNOS $=33.3 \mu \mathrm{M}$

$\mathrm{e} / \mathrm{n}=343$

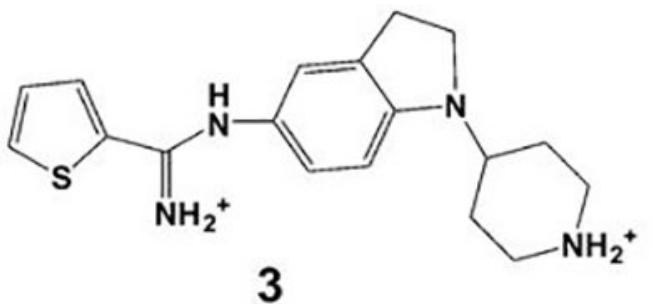

$\mathrm{IC}_{50} \mathrm{nNOS}=0.11 \mu \mathrm{M}$

$\mathrm{IC}_{50}$ eNOS $=40.5 \mu \mathrm{M}$

$\mathrm{e} / \mathrm{n}=415$

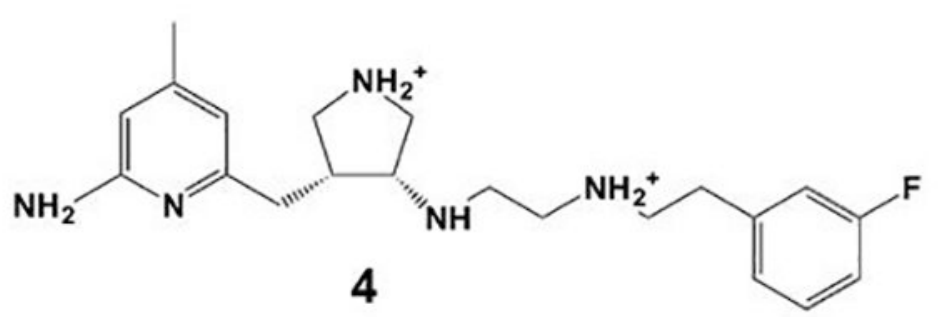

$\mathrm{K}_{\mathrm{i}} \mathrm{nNOS}=0.005 \mu \mathrm{M}$
$\mathrm{K}_{\mathrm{i}}$ eNOS $=20.3 \mu \mathrm{M}$
$\mathrm{e} / \mathrm{n}=4,060$

Figure 1.

Structures of thiophene-2-carboximidamide compounds 1-3 and one of our more selective aminopyridine inhibitors (4). The protonation state and charge when bound to NOS is shown. The $K_{\mathrm{i}}\left(\right.$ or $\left.\mathrm{IC}_{50}\right)$ values listed were determined with the human enzymes for $\mathbf{1},{ }^{10} \mathbf{2},{ }^{7}$ $3,{ }^{8}$ and 4.11 


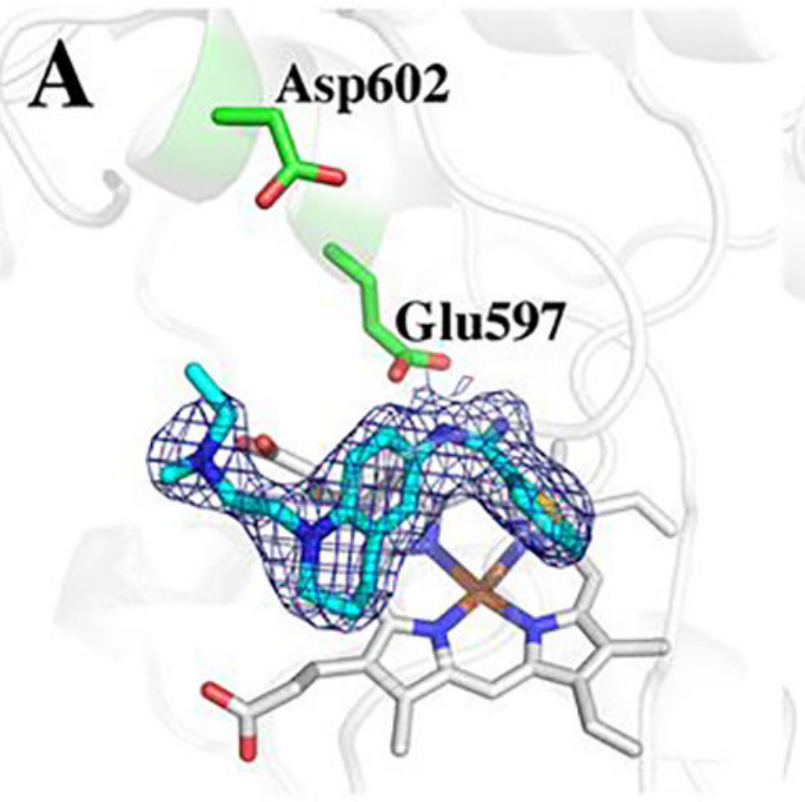

\section{B}

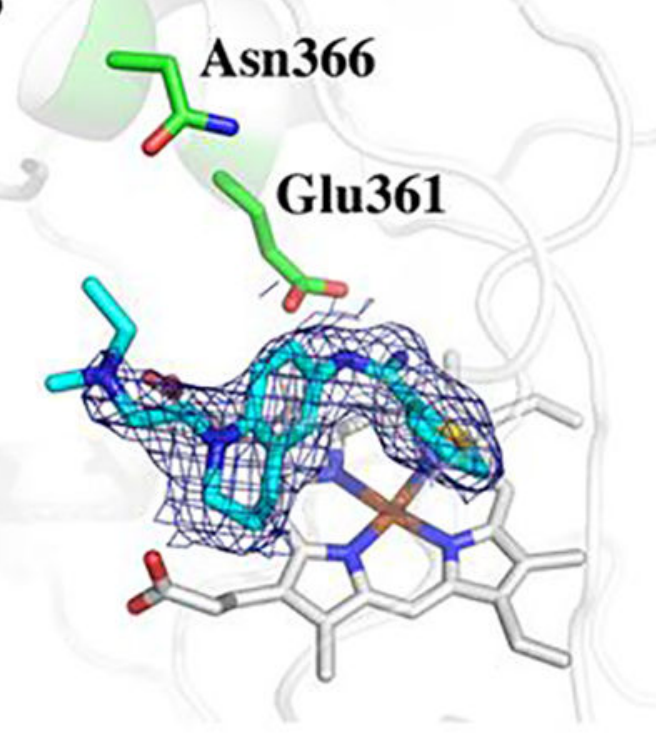

C

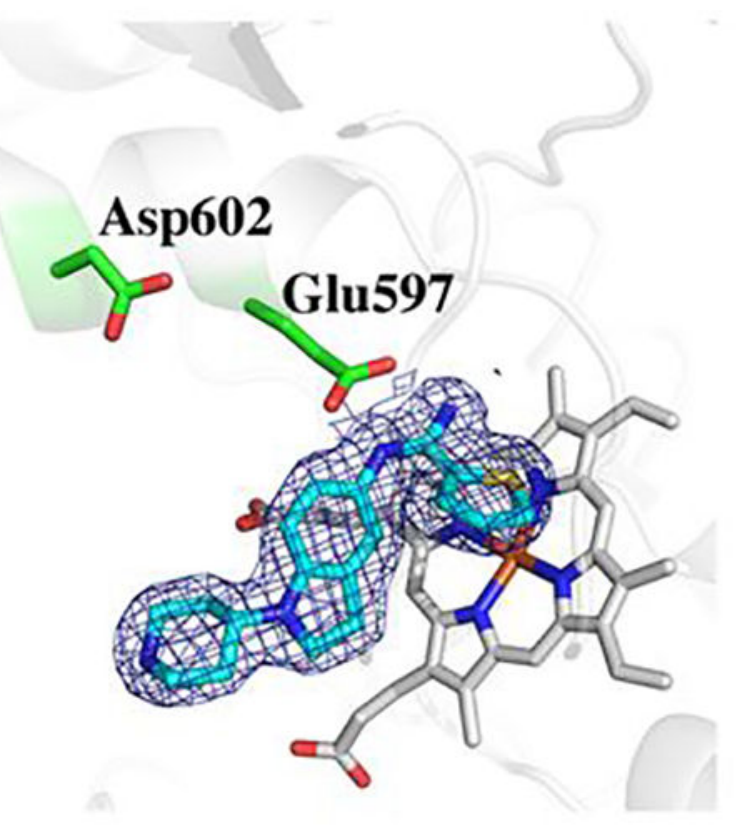

\section{D}

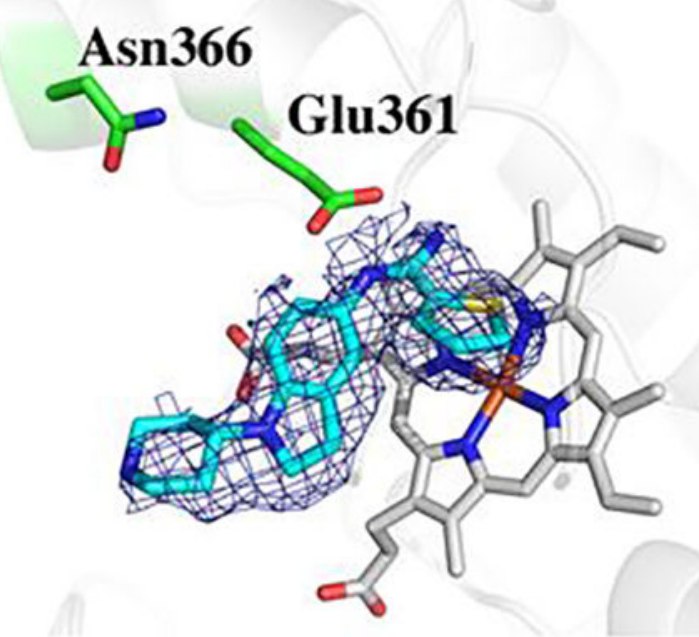

Figure 2.

2Fo-Fc electron density maps contoured at $1.0 \sigma$ for $\mathbf{2}$ and $\mathbf{3}$ bound to human enzymes. A) nNOS-2; B) eNOS-2; C) nNOS-3; D) eNOS-3. 


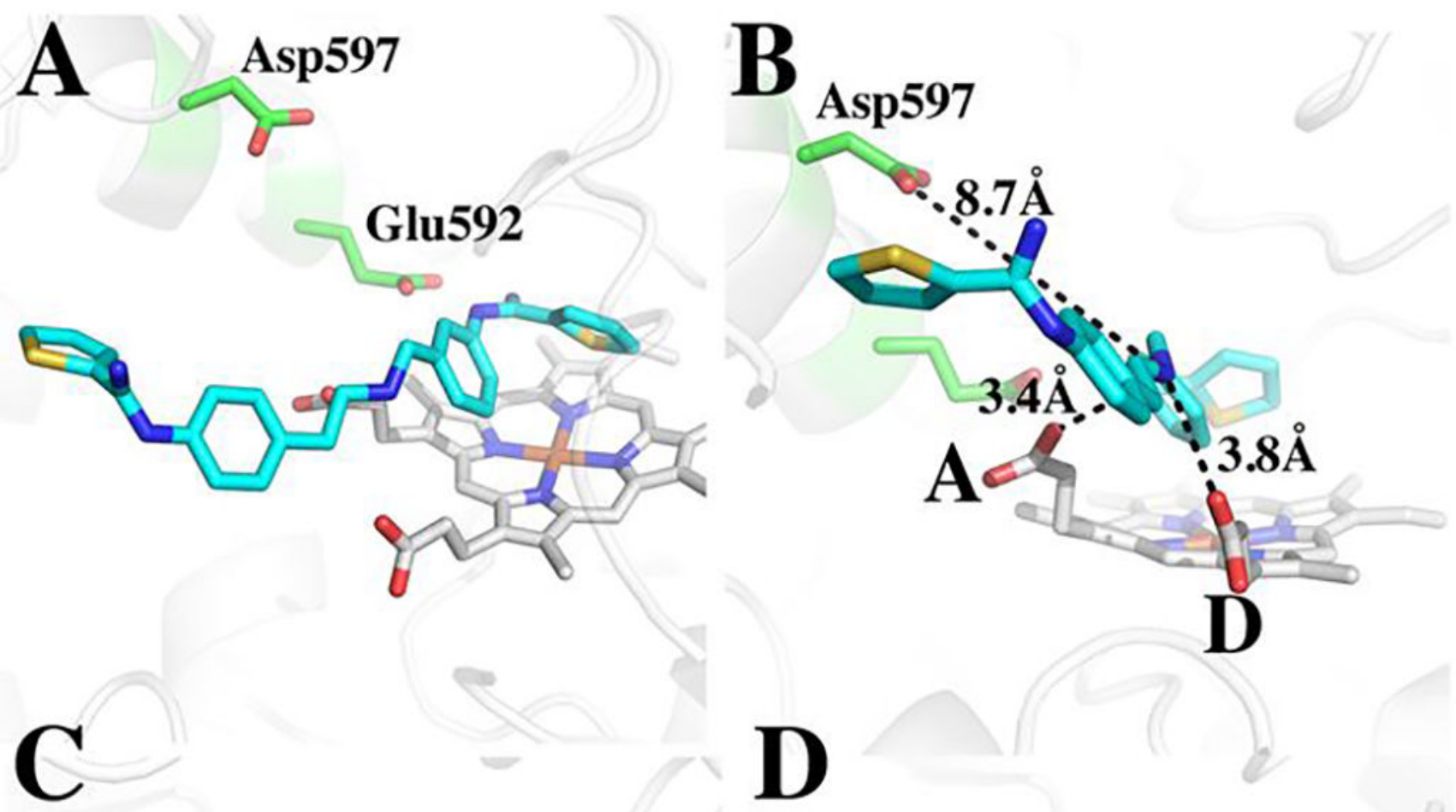

\section{Asp602}

\section{Asp602}
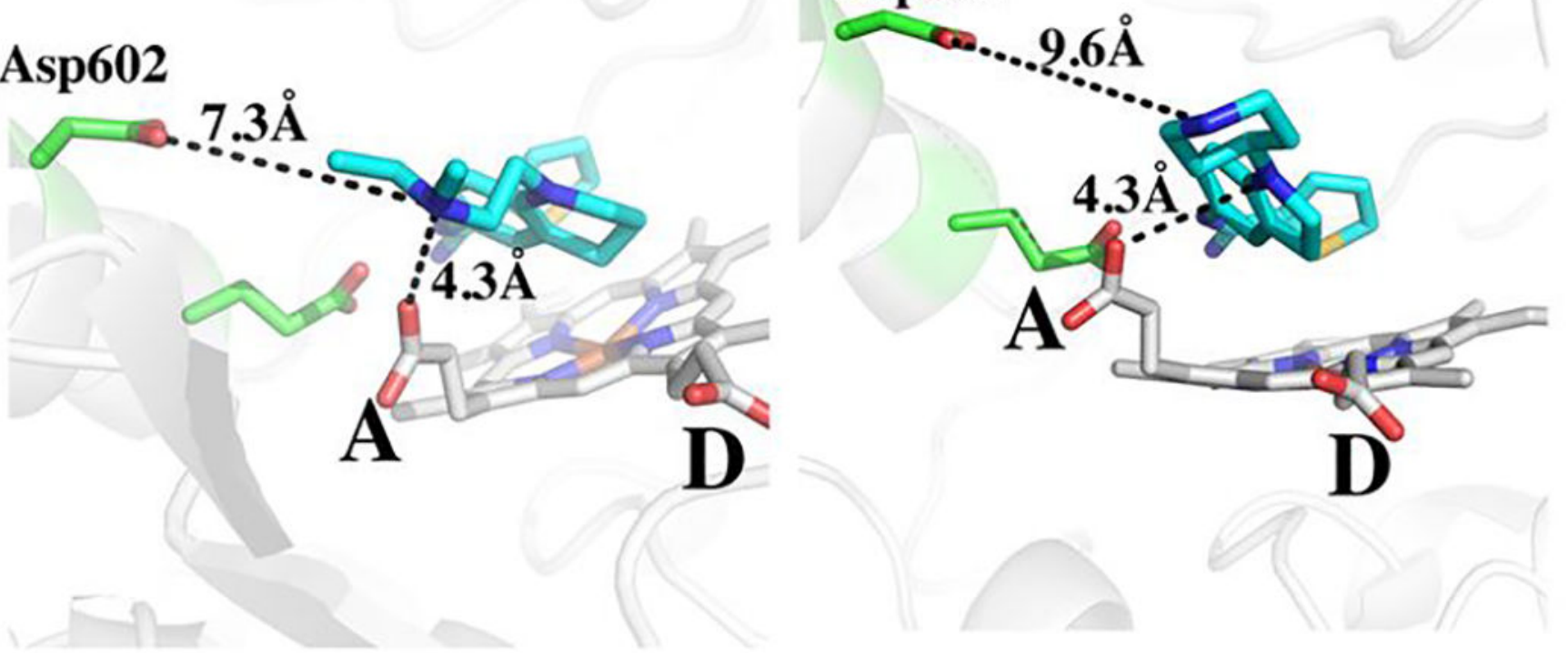

Figure 3.

Comparison of binding modes for 1 (A and B in two different views, PDB code 4KCL) bound to rat nNOS, and 2 (C) and $\mathbf{3}$ (D) bound to human nNOS. In panel $\mathrm{C}$ the distance from the tetrahydroquinoline $\mathrm{N}$ atom to propionate $\mathrm{A}$ is $4.3 \AA$, from tail amine to propionate A is $3.7 \AA$ (not shown), and to Asp602 is 7.3 atom to propionate $\mathrm{A}$ is also $4.3 \AA$, from the piperidine $\mathrm{N}$ atom to propionate $\mathrm{A}$ is $5.7 \AA$ (not shown), to Asp602 is $9.6 \AA$. 


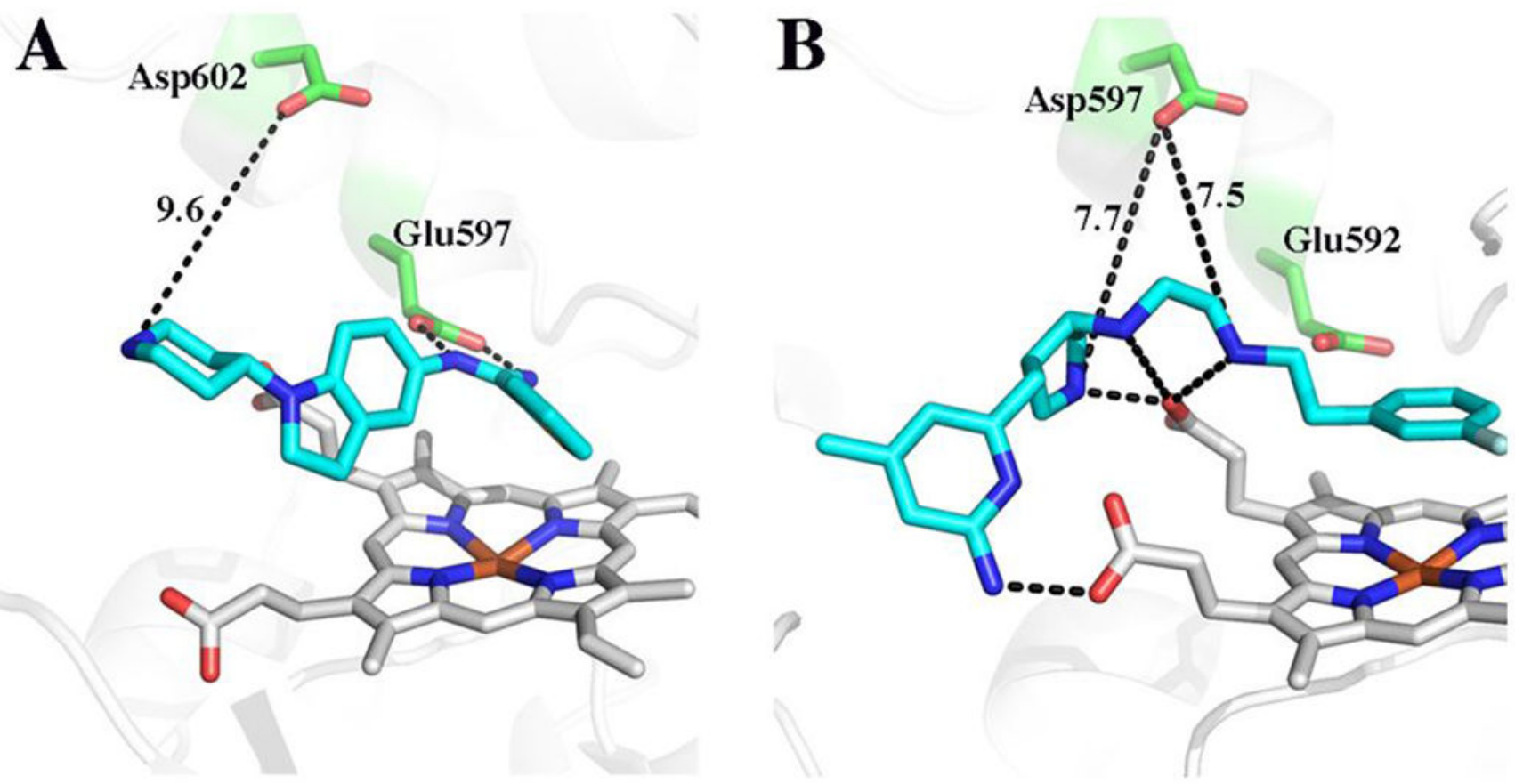

Figure 4.

A comparison of the $\mathbf{3}$ bound to human nNOS (panel A) and $\mathbf{4}$ bound to rat nNOS (panel B, PDB code 3JWS). Key distances between the active site Asp and charged groups on the inhibitor are indicated. The unlabeled dashed lines are potential H-bonds ranging from $2.5-$ $3.4 \AA$. 
Table 1.

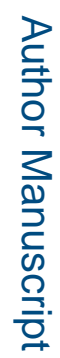

Results of thermodynamic integration calculations to determine $\mathrm{p} K \mathrm{a}$ for $\mathbf{2}$ and $\mathbf{3}$ free in solution and bound to nNOS or eNOS. The large $\mathrm{H}$ atom is the one that titrates.

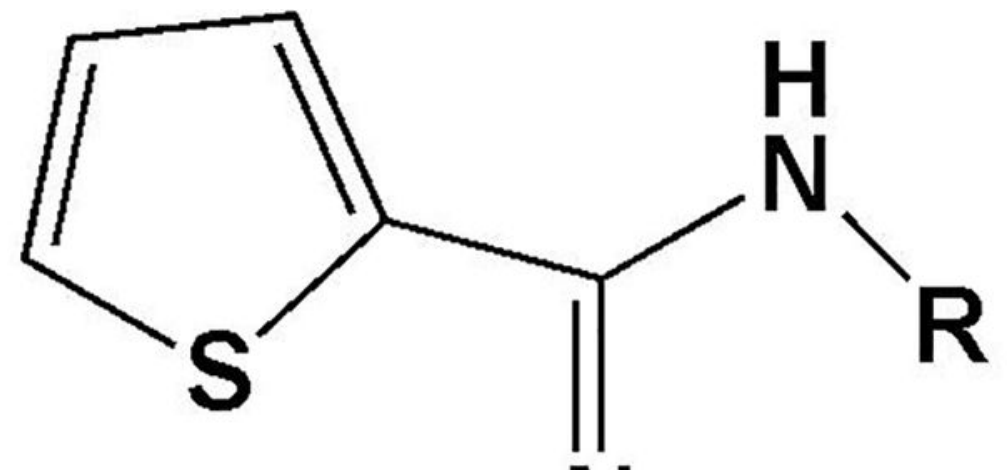

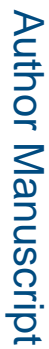

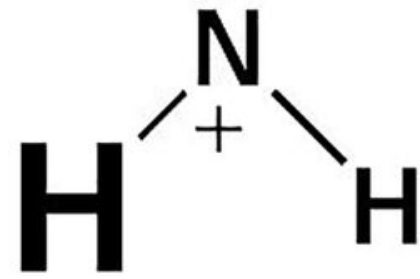

\begin{tabular}{|l|l|l|l|}
\hline & $\boldsymbol{\Delta G} \mathbf{~ k c a l} / \mathbf{m o l}$ & $\Delta \mathbf{\Delta G} \mathbf{~ k c a l} / \mathbf{m o l}$ & $\mathbf{p K a}$ \\
\hline $\mathbf{2}$ free ligand & 10.145 & & 6.98 \\
\hline nNOS-2 & 56.056 & 45.911 & 18.86 \\
\hline nNOS-2 D602N & 40.688 & 30.522 & 14.88 \\
\hline 3 free ligand & 8.016 & & 6.98 \\
\hline eNOS-3 & 33.406 & 25.309 & 13.55 \\
\hline eNOS-3 N366D & 64.200 & 56.184 & 21.52 \\
\hline
\end{tabular}


Table 2.

MM_PBSA calculations for 3 bound to human eNOS and nNOS, and to the in silico generated mutants. $\Delta \mathrm{G}_{\mathrm{exp}}$ was derived from the published $K_{\mathrm{i}}$ values. ${ }^{8}$ In order to place the calculated values on the same scale as experimental, the $\Delta \mathrm{G}_{\mathrm{calc}}$ and $\Delta \mathrm{ELEC}_{\mathrm{calc}}$ for wild type $\mathrm{nNOS}$ were normalized to $\Delta \mathrm{G}_{\mathrm{exp}}$ for nNOS. These normalized values are in parentheses.

\begin{tabular}{|l|l|l|l|}
\hline Enzyme & $\boldsymbol{\Delta G}_{\text {calc }} \mathbf{~ k c a l} / \mathbf{m o l}$ & $\Delta \mathbf{E L E C}_{\text {calc }} \mathbf{k c a l} / \mathbf{m o l}$ & $\Delta \mathbf{G}_{\text {exp }} \mathbf{k c a l} / \mathbf{m o l}$ \\
\hline nNOS wt -3 & -63.31 & -433.17 & -8.96 to -9.20 \\
\hline eNOS N366D -3 & $-65.03(-9.70)$ & $-360.49(-7.87)$ & \\
\hline eNOS wt -3 & $-56.46(-8.43)$ & $-331.27(-7.23)$ & -5.46 to -6.48 \\
\hline nNOS D602N $\mathbf{- 3}$ & $-56.89(-8.49)$ & $-409.10(-8.92)$ & \\
\hline
\end{tabular}

